Administrative Issues Journal: Connecting Education, Practice, and Research, Winter 2017, Vol. 7, No. 2: 47-56. DOI: 10.5929/2017.7.2.4

\title{
Addressing uncertainty during workplace change: Communication and sense-making
}

\author{
Rich Parsells, Ph.D. \\ St. Edward's University, Austin, Texas
}

\begin{abstract}
Change is a commonplace occurrence in today's organizations. A number of scholars suggest that communication strategies during organizational change are an important element to the success of a change initiative, yet such strategies are not given primacy in the research literature. The purpose of this paper is to add to the discourse on communication and workplace change initiatives by reporting on a research project that explored communication actions which were employed and viewed as useful by those experiencing a change in the workplace. This paper presents the findings that emanated from the study and explore their meaning in relation to selected scholarly literature on communication and change. Suggested implications for practice and future research are included.
\end{abstract}

Keywords: change management, communication and organizational change, change strategies, communication strategies

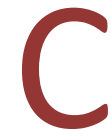

hange is a commonplace occurrence in today's organizations. To survive in an extremely competitive marketplace, organizations and their employees undergo change frequently. In addition to competitive factors, political, economic, social, and technological elements contribute to this dynamic environment and extend the need to adapt and adjust to changing conditions to the public and nonprofit sectors as well (Bryson, 2011). Therefore, the ability to manage change and to learn from this experience is viewed as a key competency for sustainability and competitiveness for most organizations in all sectors of our economy (Burke, 2014; Burnes, 2009; Connor, 1998).

However, while change management processes are employed and followed, a high percentage of change efforts have been, and continue to be, judged unsuccessful by upper management (Armenakis, Harris \& Field, 1999; Clegg \& Walsh, 2004; Hodges \& Gill, 2015). Various reasons are posited for this lack of success, from the failure to involve all organizational players in the change process (Clegg \& Walsh, 2004) to improper management strategies during the implementation and institutionalization phase of the change initiative (Armenakis, Harris \& Field, 1999; Real \& Poole, 2005). All, however, appear to agree that employees are the critical link between the established goals of an organization and their successful outcomes. This suggests that how well employees understand the change, perceive it as having value, and are provided proper support and guidance during the implementation of the change, influences the ability

PARSELLS / DOI: 10.5929/2017.7.2.4 
of employees to perform their critical link function through the successful implementation of the goals related to the change.

In addition, those who study change from the lens of a transitional phenomenon suggest that there are natural phases, with concomitant internal feelings and emotions, that occur as one transitions through a change (Adams, Hayes \& Hopson, 1977; Bridges, 2009; Nortier, 1995; Taylor, 2000). As one moves towards a new state of being, they are moving away from an existing one and, therefore, can experience a sense of loss. This possible sense of loss, along with new variables of work that emanate from the transition, leads to uncertainty and confusion, regardless of whether the change is viewed as a positive or negative event from its inception. The prevalence of uncertainty and confusion causes a heightened need for sensemaking during this time-a need to develop plausible rationale for ongoing events (Weick, Sutcliffe, \& Obstfeld, 2005). Some of the constructs of sense-making, as described by these scholars, are the observing and labeling of patterns, retrospectively; simultaneously acting and thinking on the meaning of the results of that action; and the use of interpersonal communication to assist in clarifying tacit to explicit understandings among members of the work team, a social construction of meaning. Therefore, sensemaking is a combination of actions and thoughts, both individually and with coworkers, to organize and make meaning of the messiness that comes with change.

As communication is observed as an important feature of sense-making, communication strategies during organizational change have been noted to be an important element in the success of any change initiative (Frahn \& Brown, 2007; Lewis, 2006; Miller, 2012). Russ (2007) classifies the communication strategies used during change as programmatic or participatory. Both have benefits and limitations. Programmatic strategies can be viewed as top-down and one-way modes of communication. They are highly efficient, allowing for a wide reach, and the quality of the message can be controlled. However, this method is limited as receivers are not able to negotiate the meaning of the message with the sender. Participatory strategies place the employee as an active and involved participant in receiving and helping to clarify the message and its meaning. These strategies are viewed as democratic and allow participants to negotiate and construct meaning. At the same time, they have low efficiency, and there are risks in the quality of the communication as these strategies usually require the use of numerous messengers. The benefits and limitations inherent in both suggest possible consideration of strategies that combine the positive elements of each.

\section{Purpose}

While the above discussion appears to make a strong case that communication is a critical element in the implementation of change, communication strategies have not been given primacy in the research literature (Burke, 2014; Burnes, 2009; Russ, 2007). This suggests the need to further investigate communication factors that aid in the successful implementation of change in the workplace. The purpose of this paper is to add to the discourse on communication and workplace change by reporting on a research project that explored communication actions that were employed and viewed as useful by those experiencing a change in the workplace. This paper will present the findings that emanated from the study and explore their meaning in relation to selected scholarly literature on communication and organizational change.

PARSELLS / DOI: 10.5929/2017.7.2.4 


\section{Method}

The study took place in a quasi-governmental organization located in the south-central region of the United States. The organization operates four general business lines within an operating budget of approximately 650 million, employing close to 2,500 individuals. The workplace change included new budgeting software and revisions to the chart of accounts, which led to a revised format for presentation of the budget to the board. Management, for the most part, utilized a top-down programmatic communication strategy to alert staff of the process and changes to the established schedule. Participatory communication strategies were used later in the change process after line managers expressed concern for the need to have better understanding of the reasons for modifications to established timelines and other programmatic aspects related to the change initiative.

Participants were drawn from a potential pool of 30 employees whose primary function was support of the budget process. Nine individuals responded to an email from the corporate budget manager that detailed the study, and these respondents became the study's participants. Six were financial analysts, and three were front-line managers. There was a nearly equal number of male (four) and female (five) participants, representing a wide range of work tenure, from three months to 29 years. Data were collected using a combination of strategies, semi-structured interviews, and completion of critical incident reports. Three personal interviews and two critical incident reports were conducted with, and completed by, each participant over the course of the change, which was a period of six months. This method was selected to capture each participant's perspective of their experiences as they unfolded throughout the change. All study participants were receptive to, and supportive of, the change initiative, and, therefore, the study focused on the implementation phase of the change.

Interview transcripts and critical incident reports were analyzed through the use of open coding to capture units of data. The units of data were then classified into categories of similar properties and transposed onto matrices that allowed for further analysis and distillation of the data. Axial coding was then conducted, allowing for identification and refinement of salient categories and their potential relationship. Further analysis of these secondary codes led to the identification of patterns, or themes, the results of which are presented as findings (Strauss \& Corbin, 2007). Member checks were employed to enhance trustworthiness of the data, and participants were assigned pseudonyms to maintain their anonymity.

\section{Findings}

Three themes were identified: experimentation and communication were critical to meaning making; understanding of context, and requisite revisions to plans, for each phase of the change initiative enhanced participants ability to adapt and adjust accordingly; and, expressions of appreciation from management were valued. A narrative along with selected reports of study participants are presented for each theme, allowing for deeper analysis and rich illustrations of the findings.

The first theme aligns with a number of concepts contained in the literature on change communication and sense-making. The combination of taking action through experimentation in addition to dialogue with co-workers for help in problem-solving and/or confirmation of beliefs aligns with the concept of "socialmutual understanding," a shared interpretation and understanding through interaction with others, a form of meaning creation ("A Critical Analysis of Communication Approaches," 2012). In addition, this theme closely resembles the concept of sense-making as defined by Weick, Sutcliffe, and Obstfeld (2005)

PARSELLS / DOI: 10.5929/2017.7.2.4 
as the "interplay of action and interpretation" (p. 409) and includes such factors as being action oriented, observing patterns retrospectively, and involving the social system of the work environment in one's meaning-making. Examples of this finding are represented in the following reports from a selected number of participants in their response to a question concerning actions and resources used to assist with learning during the change process.

Roy, a line manager with an extensive amount of tenure, responded:

I had to learn a new tool. Well, that's the easiest thing, the mechanical part of it, so basically working with the vendor and with the rest of the team. The vendor showed us how, we had a manual, yet it was hands on and I asked other folks, peers, what are you doing here? Hey, when I did this this is what happened... we were basically testing as we implemented. I'm not good with manuals or even training. I could do it, but it is not my preferred style. I mean show me how to get in the system and I'Il try to figure it out by myself and then if I can't I will call someone else that has more knowledge.

Pete, a financial analyst, with several years of tenure, shared a similar perspective:

We had training on the new system. Once we got past the training it was more hands-on learning because we were having to set up all of our own reports within the system. We usually work in groups, we were all fairly new to the system. There would have been very few people that really would have been able to help us. I didn't find the manual to be as helpful because the manual wasn't specific to what we were working on. It was more general and of course every set up for each company is going to be different. Sometimes we did figure it out on our own, and then we wanted to know what exactly did we do and what is it going to look like. It was trial and error and sometimes, you know, we would get it, and once the trial and error didn't work we contacted the consultants. Some problems definitely had more options [possible solutions] than others, but once you exhausted those, then definitely contact the consultants.

Mike, a financial analyst, with several years of tenure, expressed this perspective:

I wouldn't quite call it training, and the manual, yeah, the manual helped a little bit, but there was very little training. It was more either off the clock I learned or with another employee. I felt like two of us really know the system well, he taught me a lot and I taught him, and also just asking the consultants when they were here, I learn by doing, I'm not used to formal, like you know we need to have a meeting in order for me to learn about this from 4:30 and 5:00. I don't ask questions if I'm stuck and I'm stuck for a reason, whether it be my own fault or, you know, I just don't know how to pass that step. I don't sit there and give up in one second, like oh I can't do this. I really try to solve it and only when I don't solve it or can't solve it do I actually ask a question, the challenge to me is trying to solve it. To me there is no challenge in getting someone else to tell me how to do it.

Becky, a financial analyst with several years of tenure, responded to the question in a similar manner:

We did have training from the [software vendor] but it wasn't that great. You had to figure it out on your own. We got a manual, but I didn't use it all that often to be honest. I used it a couple of times but not a lot. It seemed to be kind of hard to find information in it that I would be looking for. I usually prefer manuals because I hate to bug people, but in this case, it wasn't helpful. I knew

PARSELLS / DOI: 10.5929/2017.7.2.4 
that [a coworker] had taken an active interest in the tool. He was really spending a lot of time with it, I asked him a lot about how to use the tool and get information that I wanted from it. [Another coworker] was also a great resource for me, he is very approachable, and he is on the same level I am.

The second theme appears to be supportive of the positions of scholars who advocate for ongoing and consistent communication that strives for clarity, the reduction of ambiguity in one's work, an understanding of the expectations of management, and the use of participatory communication strategies (Duck, 1998; Lewis, 2006; Russ, 2007). While study participants were receptive to the change, they all reported experiencing uncertainty and frustration in their work with the new software system and the ongoing changes within tight timeframes that occurred in the development of the new chart of accounts and the board presentation format. It appears that an understanding of the strategic thinking of leadership, the larger picture, along with a participatory role provided assistance in placing the actions associated with the change in an understandable context, and, in a few cases, provided an added benefit of deeper insight into one's role and function. This view is represented in the following responses to questions regarding the process of learning utilized by study participants.

Gina, a line manager with an extensive amount of tenure described how her involvement in strategy discussions with other managers was helpful:

I was involved in some very high level strategic meetings with our upper management to hear their thinking. We got to do some brainstorming sessions about our goals, what does success look like here, and hearing feedback from others in the room and coming to some consensus of what we really needed from upper management to kind of set the tone or give some guidance... it helped us being there and being part of the process rather than just being told what was going to happen after it was completed.

Gina further adds:

Staying in the loop on the strategic level, the budget side, that's a very core part of my job, but getting the time to really have those discussions either being in the meetings, which I didn't necessarily have to be at all the meetings, but having discussions with those that were in the meeting to stay up with what was going on there because my goal this year was not just communicate back to [the operating units] about the numbers. I wanted to at least communicate, yeah, here are the numbers, but here are the strategies behind the financial objectives so they could understand what we were trying to achieve and not just worry about their little small set of numbers. [I was] hoping to get them to see the bigger picture and see how all of this fits together.

Bill, an analyst with an extensive amount of tenure reported the following:

The business plan process is pretty much like [the organization] itself, it is so big. It's not a process where any one person in the room can stand up and say I have a complete understanding, so if someone comes up with a different idea, or what for them is an objection or concern, I like to sit down and talk about it to see where it is leading because, more often than not, their concern may turn out to be a very valid one. The ability to participate in, what became, weekly department meetings for the purpose of discussing the status of the [change] process and reasons behind

PARSELLS / DOI: 10.5929/2017.7.2.4 
modifications to our plans proved helpful to me in my understanding of how all of different stages of the plan were unfolding and reasons behind the departure from the plan.

Becky, the financial analyst with several years of tenure, added another dimension of the assistance provided from the frequent meetings that occurred regarding the change process:

Throughout this process I was able to learn more about what my customers, my internal community service customers that I'm actually preparing a budget for, what they care about, and what is important to them. Some of that is just me being new to [the business unit]. We met with each operating unit to talk about their budget. That is definitely how the learning happened, just sitting down with them one on one. The meetings that focused on higher level aspects of our change also helped me strategically, like how [business unit] fits into the [organization] budget overall, what management plans to see in the next five years and even ten years. It really helped me learn that because I had no idea until the budget process started what we were doing in the long term.

Helen, a financial analyst with a limited amount of tenure, shared a similar perspective as reported by Becky:

I found the department meetings very helpful for several reasons. They provided me with updates on the process which allowed me to gain added insights into the reasons for the new systems, and answered a number of questions I had that could not be answered except by corporate. Most helpful was, I would say, developing a network [of colleagues]. I think that has enabled me to learn something new by developing that network. The training classes and the department meetings provided me an opportunity to talk to more people and learn more things about the process.

The final theme could be associated with the recognition and celebration of accomplishments as asserted by a number of change management scholars (Bridges, 2009; Kotter, 2014). Aside from celebration serving as a ritual to mark the beginning of a "new normal," communicating success along with empathy appears to have addressed participants' personal efficacy and had the potential of forming a strong achievement-oriented group identity. This is represented in the quotes from selected participants' responses to a question about their thoughts and feelings near the completion of the change process, reacting to the news that the organization's leadership and board approved of the final products from the change initiative while applauding and acknowledging staff efforts and hard work in this process:

June, a financial analyst with a couple of years of tenure shared how she felt when she heard that the board approved the final document and verbally applauded and acknowledged staff efforts:

Some personal feelings that occurred from hearing of leadership's approval included those of accomplishment, pride, and success. I played a role in a process that turned out to be well received and I was extremely happy to be a part of it.

Roy, the line manager with an extensive amount of tenure shared that he had attended the board meeting and reported these feelings:

I was relieved and joyous when it ended successfully, the pleasure that our executives and general manager had done a really excellent job of presenting the information and fielding the questions and lots of support from the board to our staff. Lots of questions that were going down the path of giving us more money which we always like to hear. More money equates to support and reward of our efforts.

PARSELLS / DOI: 10.5929/2017.7.2.4 
Becky, the financial analyst with several years of tenure also attended the board meeting and shared the following:

I didn't know what was going to happen. I also felt confident because I felt like we had support for all of our numbers. I felt like we had prepared our [executive manager]. Definitely, I was confident, curious [as to the kind of questions that would be asked]. It went really well. I think they [board members] were very receptive. I think they really appreciated it [new board presentation format]. It was good for me because I got to meet board members that I probably would have never gotten a chance to meet so I enjoyed it for sure. It was interesting just hearing what they asked questions about, and kind of where they were coming from. For the most part I found out that they loved us [business unit] and that was a good feeling. That was reassuring of our work and what they viewed of our performance.

Lori, a line manager with an extensive amount of tenure, reported an added dimension as she shared her thoughts and feelings from her attendance at the board meeting, knowing that her department has been considered a candidate for downsizing, which would be part of ongoing discussions as the decision-making process for the final budget unfolds:

I guess you could say I am ambivalent...I feel good that we accomplished a major revision to our processes, and appreciate the kind words and praise from the board...I feel they were sincere. At the same time, I am hopeful and cautiously optimistic as to the future of my department...while discussions will continue on our future, the revised budget process, and format, may provide sufficient information to support our continuation in some form or to some degree. Our participation in this successful project may add credibility to our views with the board.

\section{Implications for Practice}

These findings suggest several implications for practice. First, while support for the early stage of planning and development for a change is important, there also appears to be a critical need for communication during the implementation phase where much uncertainty and confusion can occur. In addition, it appears that sense-making, the act of creating plausible rationales for the messiness that comes with change, is a social phenomenon that occurs within established communities of workers. This would suggest the need for management to assist in strengthening intragroup communication, through such means as arranging physical space strategically that will allow for, and encourage, interactive dialogue; conducting frequent meetings of working groups to discuss and problem-solve issues that arise; allow for experimentation and the sharing of learning and ideas from this experimentation among team members and other related coworkers; and, advocate for information in areas that need to be addressed.

Moreover, while programmatic forms of communication may have provided some timely information on the change process, participatory communication was the mode of communication that was reported as having a salient effect on participant's understanding of the reasons behind actions taken as the change process unfolded, along with an added benefit of contributing to participants' insights of their functions within the larger context of the organization. It was the understanding of the context of the change, and the dialogues which formed this understanding, that were reported as being helpful in participant's performance of their roles during the process of change. This would suggest a need to seek out opportunities for the use of participatory communication methods to enhance the contextual understanding of all employees during a change process. This would also allow the co-benefits of

PARSELLS / DOI: 10.5929/2017.7.2.4 
providing for more social construction of meaning and in helping employees learn and continue to develop their problem-solving skills. Management may play a significant role with enhancing problem-solving skills by encouraging and rewarding intra- and inter-department problem-solving through stated expectations and incorporating same in the performance appraisal system.

Lastly, success can enhance confidence and competence, and the recognition of success by management through spoken and/or written words can send messages of personal and group mastery along with a sense of personal value. This sense of accomplishment and competence can be found in the construct of self-efficacy as defined by Bandura $(1977 ; 1986)$. He posits that those who possess high levels of selfefficacy will take more initiative and are more accomplishment-focused by exhibiting persistence during difficult situations. A later meta-analysis found the concept of self-efficacy having a strong relationship to high levels of work-related performance (Stajkovic \& Luthans, 1998). Given the current and future projected pace and prevalence of change, high levels of self-efficacy among the workforce would appear to strengthen an organization's capacity to handle ongoing and unplanned change.

\section{Conclusion}

The findings from this study support the constructs found in the concept of sense-making. Moreover, findings indicate that participatory communication strategies have a significant effect on employees' ability to adapt and adjust during the implementation phase of a change process. Lastly, due to the commonality of change, it appears critical to build staff competencies in their handling of change in an ongoing manner. Reports from this study suggest that management's recognition of employees' good work and effort builds self-efficacy, which can lead to developing an organization whose human resources are more accomplishment-oriented and persistent in the face of change.

There are limitations to this study. First, due to the use of open ended interview questions, data was not obtained on all aspects of communication used during this change initiative. It may be of benefit if future studies structured questions in order to obtain broader and deeper perspectives on the benefits and limitations of various modes and strategies of communication for comparison to the literature. Second, this is a single case study with limited participants who were of the same professional field and worked within the same corporate culture. Future studies should be conducted that explore communication and sense-making actions during the implementation phase of a change for those in different professions and from different organizations in order to assess similarities and differences with the findings from this study.

References

A critical analysis of organizational approaches for implementing organizational change. (2012). Business and Management Review, 1(11), 27-35.

Adams, J., Hayes, J., \& Hopson, B. (1977). Transition: Understanding and managing personal change. Montclair, NJ: Allanhead, Osmun \& Co. Publishers.

Armenakis, A. A., Harris, S. G., \& Field, H. S. (1999). Making change permanent: A model for institutionalizing change interventions. Research in Organizational Change and Development, 12, 97-128.

PARSELLS / DOI: 10.5929/2017.7.2.4 
Bandura, A. (1977). Self-efficacy: Toward a unifying theory of behavioral change. Psychological Review, $84,191-215$.

Bandura, A. (1986). Social foundations of thought and action. Englewood Cliffs, NJ: Prentice-Hall.

Bridges, W. (2009). Managing transitions ( $3^{\text {rd }}$ ed.). Philadelphia, PA: Capo Press.

Bryson, J. M. (2011). Strategic planning for public and nonprofit organizations ( $4^{\text {th }}$ ed.). San Francisco: John Wiley \& Sons.

Burke, W. W. (2014). Organization change: Theory and practice $\left(4^{\text {th }}\right.$ ed.). Thousand Oaks, CA: Sage Publications.

Burnes, B. (2009). Managing change. New York: Prentice Hall.

Clegg, C., \& Walsh, S. (2004). Change management: time for a change! European Journal of Work and Organizational Psychology, 13(2), 217-239.

Connor, D. R. (1998). Leading at the edge of chaos; How to create a nimble organization. New York: John Wiley \& Sons, Inc.

Duck, J. (1993). Managing change: The art of balancing. Harvard Business Review, 71(6), 109-118.

Frahn, J., \& Brown, K. (2007). First steps: Linking change communication to change receptivity. Journal of Organizational Change Management, 20(3), 370-387.

Hodges, J., \& Gill, R. (2015). Sustaining change in organizations. Thousand oaks, CA: Sage Publications.

Kotter, J. P. (2014). Accelerate: Building strategic agility for a faster-moving world. Boston, MA: Harvard Business Review Press.

Lewis, L. K. (2006). Employee perspectives on implementation communication as predictors of perceptions of success and resistance. Western Journal of Communication, 70, 23-46.

Lewis, L. K., \& Seibold, D. R. (1998). Reconceptualizing organizational change implementation as a communication problem: A review of literature and research agenda. Communication Yearbook, 21, 93-151.

Miller, K. (2012). Organizational communication: Approaches and processes ( $6^{\text {th }}$ ed.). Boston: WadsworthCengage Learning.

Nortier, F. (1995). A new angle on coping with change: Managing transition! Journal of Management Development, 14(4), 32-46.

Russ, T. L. (2007). Communication strategies for implementing organizational change. Association for Business Communication $72^{\text {nd }}$ Annual Convention, October 10-12, 2007, Washington, DC.

Stajkovic, A. D., \& Luthans, F. (1998). Self-efficacy and work-related performance: A meta-analysis. Psychological Bulletin, 124(2), 240-261.

Strauss, A., \& Corbin, J. (2007). Basics of qualitative research: Techniques and procedures for developing grounded theory ( $3^{\text {rd }}$ ed.). Thousand Oaks, CA: Sage Publications.

PARSELLS / DOI: 10.5929/2017.7.2.4 
Taylor, P. G. (2000). Exploring the roles of grief and grieving in coping with lifelong change. International Journal of Lifelong Education, 19(6), 525-534.

Weick, K., Sutcliffe, K. M., \& Obstfeld D. (2005). Organizing and the process of sensemaking. Organization Science, 16(4), 409-421.

\section{About the Author}

Rich Parsells, Ph.D. (richp@stedwards.edu) holds a Master in Public Administration and a Master in Business Administration from the University of Dayton in Dayton, Ohio. His doctorate degree is in Adult, Professional, and Community Education from Texas State University in San Marcos, Texas. He has over 25 years of management experience in the public and not-for-profit sectors, and has held a fulltime tenure track faculty position for the past 11 years. His areas of research interest are in organizational change, organizational culture, and adult learning.

PARSELLS / DOI: 10.5929/2017.7.2.4 